\title{
Climate Change and Inpatient Dermatology
}

\author{
R. Fathy ${ }^{1} \cdot$ Misha Rosenbach ${ }^{2}$ (I) \\ Published online: 22 August 2020 \\ (C) Springer Science+Business Media, LLC, part of Springer Nature 2020
}

\begin{abstract}
Purpose of Review Climate change represents a major existential threat facing the global community, and it has already begun to affect human health in a multitude of ways. This review highlights and discusses the implications that climate change has already had and is expected to have for inpatient dermatologists.

Recent Findings There are a variety of conditions affected by climate changes. The distribution and frequencies of infectious diseases and their vectors are changing in line with variations in climate conditions. Increased temperatures have already been associated with exacerbation of existing skin conditions, such as atopic dermatitis, and recent evidence suggests that higher temperatures will also magnify the effects of harmful ultraviolet radiation. Extreme weather events that result from climate change are followed by an array of dermatologic conditions that may be unusual for the given location. Inpatient dermatologists should be prepared to manage these potentially unfamiliar dermatologic consequences of climate change.

Summary Climate change will have widespread effects on the medical field, and inpatient dermatologists will be faced with their own unique set of challenges and practice variations. Practitioners should be familiar with the ongoing and predicted effects of climate change in their locations so that they can readily identify and treat associated conditions, and they should adjust their practice to reduce their carbon footprint and serve as a model for patients to do the same.
\end{abstract}

Keywords Climate change $\cdot$ Dermatology $\cdot$ Inpatient dermatology

\section{Introduction}

Climate change is an existential threat and one of the major challenges of our time, with scientists overwhelmingly agreeing that the process is anthropogenic in origin [1], worsening, and requires a rapid response at a global scale. The science of climate change has been clear for 40 years - though in 2019, it achieved "5-sigma" certainty, i.e., the highest level of scientific evidence possible [2]. Most discussions of climate impacts focus on projections looking decades into the future [3], but climate change already has profound impacts on human health. From increasing numbers of extreme weather

This article is part of the Topical Collection on Hospital-Based Dermatology

Misha Rosenbach

misha.rosenbach@pennmedicine.upenn.edu

1 Perelman School of Medicine, University of Pennsylvania, Philadelphia, PA, USA

2 Department of Dermatology, University of Pennsylvania, $7^{\text {th }}$ Floor Perelman Center for Advanced Medicine, South Pavilion, 3400 Civic Center Blvd, Philadelphia, PA 19104, USA events like heat waves, floods, and wildfires to food shortages caused by ecological changes and subsequent privation, migration, and associated mental health impacts, climate change is having profound impacts on people and populations across the globe. Infectious diseases due to changing habitats and geographic distribution of vectors are one of the most visible and readily attributable health impacts due to climate change.

At this moment in history it is impossible to ignore the profound impacts of the SARS-CoV-2 virus and how COVID-19 infection is impacting every aspect of society and medicine. Notably, early studies on the ongoing COVID-19 pandemic have found that individuals living in areas affected by climate change have worse outcomes and higher case rates in latitudes currently more severely affected by climate change $[4,5]$. Furthermore, the pandemic may represent the first of a series of outbreaks whose frequency was predicted to be increased due to climate change [6-8], as deforestation, food scarcity, climate refugees, and population shifts may increase the risk of novel emerging pathogens.

While many of the health-related consequences of climate change have been well-described in the literature $[9,10]$, the dermatologic impacts of climate change have only recently begun to be highlighted [11•]. The implications of climate 
change for inpatient dermatology in particular have remained unreported. This work aims to fill this gap by reviewing the dermatologic effects of climate change as pertains to inpatient practice.

\section{Background}

To best discuss the relationship between climate change and human disease, it is crucial to understand the root causes of climate change. Carbon dioxide and other greenhouse gases (GHGs) are produced primarily through the combustion of fossil fuels and deforestation - processes that also promote air pollution. After being emitted, GHGs concentrate in the atmosphere, where they absorb and trap the sun's infrared radiation that has been reflected by the Earth's surface. The level of $\mathrm{CO}_{2}$ in the atmosphere is closely related to rising temperatures. In 2018, the United Nations' Intergovernmental Panel on Climate Change set a threshold of $1.5^{\circ} \mathrm{C}$ of average warming (above the preindustrial baseline), beyond which our planet will become significantly less hospitable to human life [12].

The relationship between human activity and GHGs emission has been made more visible in the context of the COVID19 pandemic, when a relative decrease in human activity (e.g., reduced travel and consumption) has resulted in a temporary reduction in daily $\mathrm{CO}_{2}$ emissions [13] - though notably even the dramatic reductions in travel seen during regional lockdowns are below that which is necessary to achieve sufficient $\mathrm{CO}_{2}$ emission reductions to adhere to the Paris agreement goals and IPCC expert targets of limiting warming to below $1.5^{\circ} \mathrm{C}$. The Earth has existed for billions of years; the amount of $\mathrm{CO}_{2}$ currently in the atmosphere has skyrocketed since the industrial revolution, and the current level of $417 \mathrm{ppm}$ is both the highest level ever recorded in human history, and rising year-after-year.

Over time, the rising concentration of GHGs in the atmosphere has resulted in a progressively rising average planetary surface temperature. This has translated into alterations in temperature-related features (magnitude of diurnal-nocturnal temperature shifts, magnitude of annual temperature peaks and nadirs, frost dates); precipitation-related features (total precipitation, snowfall, seasonality, humidity); and atmospheric features (cloud cover; speed and direction of prevailing winds). Warmer air can hold more moisture and is associated with more severe storms and weather-related disasters.

Climate change contributes to an array of processes that have consequences for human health and dermatologic disease. These processes include variations in infectious disease vector distributions and seasonal patterns, increased frequency of extreme weather events and cutaneous consequences, and higher levels of exposure to UV radiation. Finally, because climate change and air pollution share common causative processes, a discussion of climate change and its impacts on health should also consider the impacts of air pollution. As the skin is an environmental interface, toxins and pollutants in the air can interact with the skin and contribute to flares of certain inflammatory skin diseases. It is important to be aware of these climate change-associated processes and their potential impacts on the practice of inpatient dermatology.

\section{Alterations in the Geographic Distributions of Vector-Borne and Other Infectious Diseases}

As climate patterns change, so too do the regional distributions of infectious diseases. Conditions impacted by such include both those transmitted by insect vectors whose habitats are impacted by climate change as well as some diseases that do not require a vector for transmission but are sensitive to particular climate conditions.

Lyme disease, transmitted by Ixodes scapularis tick, has historically been limited to New England and the Northeast USA, but has progressively expanded in distribution over the past several decades [14-16]. Mediating this expansion-as with that of many vector-borne diseases - is the modification of natural host and vector habitats, caused by climate change resulting in warmer weather, more mild winters, and an expanded habitat for the tick and its non-human hosts [17]. Perhaps expectedly, this expanded distribution of Lyme vectors and hosts has been associated with a concurrent rise in the number of cases of Lyme disease, rising from approximately 10,000 cases in 1995 to over 36,000 cases in $2016[18,19$, $20 \bullet$. Lyme disease now occurs in all 50 states and in parts of Canada, where previously it was unknown. For the inpatient dermatologist, these trends necessitate increased vigilance in order to recognize, diagnose, and manage Lyme disease in areas where it was not previously seen [21].

Just as with Lyme disease, climate change has also facilitated the spread of Leishmaniasis [22]. By promoting hotter and drier weather as well as droughts, climate change has gradually shifted the preferred habitats of the Lutzomyia sandfly vectors and rodent hosts of Leishmaniasis farther away from the equator [23, 24]. Leishmaniasis outbreaks have also been observed after short-term climate variation events, as seen in Colombia after El Niño-Southern Oscillation [23]. For North America, ecological niche models had predicted that the infection would become endemic in the USA [25]; shortly after that publication, the first cases of endemic Leishmania infection were reported in Texas [26].

The spread of leishmaniasis is further exacerbated by the changing climate's effects on the life cycle of the parasite, as it is expected to experience more frequent infectious cycles that will increase the opportunities for transmission [24]. Overall, even in the most conservative models, it is estimated that twice as many individuals will be exposed to leishmaniasis by 2080 [25]. Interestingly, although it is transmitted by a different 
vector (Triatomine insects), Chagas disease is predicted to have a similar northeast-ward spread in the USA as a result of climate change [27]. Between 2000 and 2018, there were 76 reported cases of Chagas disease in the USA, representing a tenfold increase over the preceding 50 years, with the associated vector now identified in 29 states [28]. The reduviid bug vector has been reported as far North as Delaware [29]. Consequently, dermatologists in at-risk areas should be prepared to treat patients who are hospitalized with these conditions, which are likely to be unprecedented at their institutions.

In addition to shifting or expanding existing regions affected by certain vector-borne diseases, climate change, in combination with global trading, has enabled the introduction and rapid expansion of vector-borne diseases that were not previously endemic to certain areas. This is best seen in the case of the Aedes aegypti and Aedes albopictus mosquitoes, which are believed to have been brought to North America through the used car and tire trades [30]. These mosquitoes serve as vectors for a number of viral diseases that may be seen by an inpatient dermatologist, including Dengue, Chikungunya, and Zika.

Dengue is a flavivirus that is originally endemic to tropical and subtropical regions of the world that has recently begun to affect more temperate regions that were previously unaffected $[31,32]$. Clinically, the virus causes an initial febrile phase accompanied by headache, myalgia, arthralgia, and a transient macular rash, with some cases developing a hemorrhagic second phase that may present with a petechial rash or profuse bleeding. Along with promoting the expansion of the Aedes vector's geographic distribution, rising surface temperatures accelerate dengue's incubation period, permitting more rapid viral transmission by the mosquito vector [33, 34]. As increased rainfall and temperatures extend Aedes's range of habitable regions into previously naïve areas, the number of cases of dengue fever has also increased, with 100-400 million new infections now recorded each year $[35,36]$. Based on climate change projections, recent models of the spread of Dengue in the USA predict continued expansion northward into temperate regions of the country, including large swaths of the Midwest and potentially cities like Indianapolis and Philadelphia [37]. Dermatologists in these regions should expect to see and manage cases of dengue in the coming decades.

Sharing common mosquito vectors, Chikungunya and Zika are also predicted to expand poleward as a result of climate change [38]. Chikungunya is caused by a togavirus and associated with severe arthralgias, high fevers, and a morbilliform rash in the acute phase, with hyperpigmentation persisting during resolution in some patients [39]. As with Dengue, there have also been outbreaks of Chikungunya associated with El Niño-Southern Oscillation [40]. Zika, on the other hand, is a flavivirus that also presents with fevers and arthralgias, but is also accompanied by headaches, distinctive conjunctivitis, and myalgias as well as a maculopapular, pruritic rash that often begins on the face and spreads caudally, sparing the palms and soles and at times accompanied by a petechial component [41, 42]. Although it originated in Africa and Southeast Asia, Zika spread to the Western hemisphere in just the last decade, with recent expansion northward into the Americas that is predicted to spread as far north as southern Canada in the next few decades [43-45]. Inpatient dermatologists across North America should anticipate a progressively rising incidence of these arboviruses.

Arboviruses are not the only viruses whose epidemiology is being altered by the changing climate; enteroviruses are similarly predicted to increase in incidence due to climate change. One such enteroviral infection is hand-foot-andmouth disease (HFMD). A common childhood infection, HFMD, is most commonly caused by a coxsackievirus and usually manifests as sores in the mouth and macules that develop into blisters on the hands and feet, as well as macules and papules on the buttocks. HFMD historically rarely affected adults, but recently severely affected adult patients have presented to emergency departments and been admitted due to the coxsackie A6 [46]. A rising incidence of HFMD has been associated with increasing temperatures, rainfall patterns, humidity levels, and heatwaves, all of which can be consequences of climate change [47-50]. As these climatic changes intensify and impact areas that had previously not seen such weather patterns, HFMD and other enteroviral diseases are expected to have longer and more intense infectious seasons [51], underscoring the importance of weather forecasting in predicting outbreaks and the role that dermatologists may increasingly play in treating the health effects of climate change.

Along with viral diseases, dimorphic fungal infections have also been found to shift in distribution and incidence due to climate change. One such fungal infection is coccidioidomycosis, which is caused by Coccidioides immitis and C. posadasii. Although it has historically been limited to the Southwestern USA, the geographic range of coccidioidomycosis has expanded broadly across the entire southwest and has recently become endemic to certain regions of Washington state [52]. This shift has been promoted by several climatic factors, including longer dry seasons, recordbreaking rainfall, and more frequent windstorms, which result in fungal spore aerosolization [53, 54]. High incidence rates are facilitated by the fact that this area contains residents who are primarily immunologically naive to this fungus [52].

Additionally, states in which the fungus is usually endemic have also seen increases in the number of cases of coccidioidomycosis, with some studies estimating that climatic factors account for $75 \%$ of this increase $[55,56]$. Recently, Gorris et al. modeled the geographic spread of coccidioidomycosis based on climate change patterns, ultimately projecting that the fungus's endemic regions will more than double over the 
course of this century by expanding north into drier states in the western USA, such as Idaho, Wyoming, Montana, Nebraska, South Dakota, and North Dakota [57]. Altogether, these patterns and predictions suggest that dermatologists in these states may soon be including dimorphic fungi on their differentials in an unprecedented way.

\section{Increased Temperatures and Extreme Weather Events}

The emission of solar radiation from GHGs in the atmosphere - the process driving climate change - results in elevated temperatures on land and in major bodies of water. While this may take the form of gradual shifts in climate in some areas, other areas have already begun to experience an increased frequency and intensity of extreme weather events as a result of this process. Increased temperatures and accelerated or amplified short-term variation in climate promote a variety of extreme weather events, including heat waves, tornados, heavy precipitation, hurricanes, and floods. Each of these consequences exacerbates or increases the risk for dermatologic disease.

Increasing surface temperatures are associated with multiple types of extreme weather events. First, heat waves have become more frequent and more severe, representing the most common cause of extreme weather event-related death in the USA [58]. To appropriately respond to such elevated temperatures, humans must dissipate body heat through eccrine sweating. However, such sweating may be impaired in a variety of dermatologic conditions, including atopic dermatitis, psoriasis, ichthyosis, systemic sclerosis, Sjogren's syndrome, and Fabry [59, 60]. Without the ability to regulate their body temperature by sweating, these individuals are at increased risk of heat-related death, often due to cardiorespiratory causes [61].

Heat waves and dryer weather also facilitate the initiation and expansion of wildfires, as has unfortunately been observed in recent years, when we have witnessed larger and more destructive wildfires than ever before. These wildfires produce significant amounts of air pollution, which, in addition to their respiratory effects, are also thought to induce flares in patients with atopic dermatitis [62•]. As we better characterize this relationship, dermatologists will be more able to predict when these events might result in a surge of flares that they must be able to manage promptly and effectively.

Infrared radiation emitted by GHGs also contributes to warming of seawater and rising sea levels, which entail a number of potential dermatologic consequences. First, similar to the effects of warmer surface temperatures on the geographic distribution and behaviors of infectious disease vectors, altered seawater temperatures has been associated with variations in the distributions and behaviors of sea animals and microbes. For instance, the Portuguese man-of-war, a potentially lethal jellyfish species that prefers warmer waters, has been observed in higher concentrations and in unusual locations, including the southeastern coastline of the USA, where there have already been large envenomization outbreaks [63, 64].

Larger studies have identified similar increases in jellyfish concentrations on a global scale, citing several climate change-associated processes as mediators of this finding, including altered seawater $\mathrm{pH}$ and salinity, increased weather extremes like the El Niño Southern $[65,66]$. With increased jellyfish concentrations comes increased jellyfish larva (planulae) concentrations, particularly due to elevated seawater temperatures. This increase in jellyfish larva amounts and distributions has been associated with a concurrent rise in cases of seabather eruption, a dermatitis caused by these planulae, particularly those of Linuche unguiculata [67]. For inpatient dermatologists, these trends in jellyfish patterns highlight a need for greater familiarity with the clinical signs and symptoms that accompany the dermatologic conditions they may cause.

Cercarial dermatitis, the "swimmer's itch" caused by avian schistosomes, is another dermatologic condition impacted by climate change. Warmer temperatures promote the spread of this dermatitis in several ways: by altering the migratory patterns of birds, promoting the growth of snails (the schistosome's intermediate host), increasing interaction between migrating birds and snails, and increasing cercarial emission rates [68-71]. Because snails thrive in the setting of excess nutrients, man-made water areas and eutrophic lakes are most at-risk of increased case rates of cercarial dermatitis, as these areas experience nitrogen and phosphorus runoff more commonly [91-73]. Particularly in these areas with these bodies of water, dermatologists should keep cercarial dermatitis in mind when treating patients with pruritic papules or vesicles that may be accompanied by fever, lymphadenopathy, edema, nausea, and diarrhea in severe cases.

Another set of microbes that will become more problematic because of climate change is the genus Vibrio, whose reproduction and proliferation are accelerated in warm water [72]. Of particular relevance for dermatologists are $V$. parahaemolyticus and $V$. vulnificus. The changing climate has extended the seasons of infectivity of these species, and studies on the incidence of their associated diseases in the USA have found increased abundance along the Pacific coast and in non-coastal states [73]. Already, these altered infection patterns have resulted in increased hospitalizations for dermatologic conditions, including wound infections, cellulitis, and sepsis [74, 75], and inpatient dermatologists should expect to see continued rises in the frequency of such cases.

Along with increased temperatures and heat waves, climate change also increases the frequency of other extreme weather events, such as heavily increased precipitation, hurricanes, 
and floods, all of which have been associated with increased transmission of waterborne disease [76-78]. According to the WHO, skin diseases are the most common medical issue after major flooding events, representing $19 \%$ of consultations [79].

Skin-related conditions associated with flooding [80•] - as well as evacuations, displacement, and overcrowding of climate refugees - include scabies [81], papular urticaria [82], eczema [83], and leptospirosis, which is transmitted by rodent urine and presents with flu-like symptoms, conjunctival injection, and a petechial rash on the palette [84]. Patients may have lacerations or traumatic injuries that develop secondary infection with a range of pathogens, from bacteria (gram positive and gram negative), fungal, dermatophytic, and mycobacterial [79]. Other traumatic events, such as animal bite injuries due to crowding on high ground, laceration from debris (both wind-borne in high winds, or water-borne due to floodwaters), can lead to direct skin trauma and/or secondary infection and dermatologic consultation [75].

Another dermatologic condition associated with flooding, as well as other extreme weather events like tornados and hurricanes, is melioidosis, a condition caused by Burkholderia pseudomallei that consists of a localized infection, abscess, ulceration, cellulitis, or necrotizing fasciitis [85, 86]. Although the causative bacterium is historically endemic to Southeast Asia and Northern Australia, the importation of infected animals is thought to have spread the bacterium to non-endemic areas, where outbreaks of melioidosis can then result from extreme weather events [87]. As such events become more common, outbreaks of melioidosis are predicted to become increasingly common as well [68, 88, 89]. Dermatologists in areas where extreme weather events have become more severe or frequent should be prepared to diagnose and treat this potentially unfamiliar condition.

\section{Increased Effects of Ultraviolet Radiation}

The harmful effects of ultraviolet (UV) radiation may be amplified by anthropogenic impacts on the climate and environment. Before the Montreal Protocol on Substances that Deplete the Ozone Layer was implemented 1987, widespread use of ozone-depleting aerosols like chlorofluorocarbons and halons resulted in a considerable reduction in the amount of UV-reflecting ozone in the Earth's atmosphere. Although the ozone layer has begun to replete itself, there are still an estimated 33,000 additional cases of melanoma and nonmelanoma skin cancers yearly that are thought to be attributable to the relative ozone deficit [90-92].

While we have successfully begun to reverse the contributions of ozone depletion to increased UV radiation effects, there is still another way that climate change can magnify UV's oncogenic effects: elevated temperatures [93]. Current estimates predict that for each 2-degree increase in average surface temperature, there will be an associated $10 \%$ increase in the carcinogenic effectiveness of UV radiation [93, 94]. This issue is further compounded by the fact that warmer weather typically motivates individuals to spend more time outside, often without protective clothing [95]. All in all, the effects of human activity on the climate are indirectly magnifying the oncogenic effects of the sun's UV radiation, which has already resulted in higher rates of various skin cancers, which are expected to continue rising in incidence.

\section{Climate Change and Inflammatory Skin Diseases}

As our climate continues to change, the inpatient dermatologist can expect their patients to experience worsening of chronic inflammatory or autoimmune diseases. One mediator of this exacerbation is the psychological and physical stresses caused by climate change and its accompanying extreme weather events, which have been associated with increased flares of diseases like atopic dermatitis, alopecia areata, vitiligo, and psoriasis [80•, 96, 97].

Air pollution from fossil fuel consumption and wildfires has also been found to promote more frequent disease flares in patients with certain chronic dermatologic diseases. Both of these processes produce a variety of pollutants in the forms of particulates and gases that induce oxidative stress and, consequently, the secretion of pro-inflammatory cytokines. Ultimately, this process promotes flares of chronic inflammatory skin diseases like atopic dermatitis [62, 98, 99]. Furthermore, some studies have suggested that, in addition to worsening existing inflammatory skin disease, air pollution may also increase the overall prevalence of such disease [100].

The severity of several autoimmune skin diseases has also been associated with climate conditions and air pollution. For example, increased temperature and small particle air pollution have been associated with increased hospitalization rates for pemphigus [101]. Similarly, climate variations have been associated with various types of flares of systemic lupus erythematosus [102]. As stated earlier, the impacts of human activity on the climate indirectly amplify the effects of UV radiation. Consequently, patients with photoaggravated diseases like lupus may experience more frequent or more severe flares of their condition. Data on this relationship are only beginning to emerge [103, 104], and further study is warranted.

Climate change and air pollution have also been found to impact other systemic inflammatory and autoimmune diseases that have cutaneous manifestations. In particular, patients were fibrotic sarcoidosis were reported to have an increased severity of symptom and worsened quality of life as a result of air pollution exposure [105]. Moreover, overall rates of sarcoidosis, as well as hospitalization rates for the condition, 
have been found to be higher in areas with more exposure to processes that are major contributors to climate change, such as intense agriculture and air transport factories [106]. As a result, inpatient dermatologists who practice in areas with such environmental exposures may be able to attribute their patients' hospitalizations, at least in part, to these processes, though further investigation is needed to better characterize this relationship.

\section{Changes in Vegetation Growth and Distribution}

As with aquatic and vector-borne dermatoses, the geographic distribution and intensity of vegetation-related dermatoses have also been altered by climate change. Because atmospheric $\mathrm{CO}_{2}$ enhances the growth of poison ivy, the production of $\mathrm{CO}_{2}$ by the combustion of fossil fuels has inadvertently caused these noxious plants to become more abundant and more allergenic [107, 108]. Similarly, other invasive allergenic plant species, like bracken and giant hogweed, are also stimulated by rising atmospheric $\mathrm{CO}_{2}$ and climate changerelated shifts in weather patterns, causing them to expand into regions where they were previously not found [109]. As a result of these processes, future inpatient dermatologists will likely see more cases of severe allergic reactions to plants, as they are predicted to become increasingly prevalent and increasingly allergenic.

\section{Conclusion}

Climate change has already begun to impact human life through the associated extreme weather events and its detrimental health effects. This imminent issue has multiple implications for specialists in dermatology. Infectious diseases of the skin will appear in regions and seasons where they were previously undescribed. Existing skin disorders will be exacerbated by weather and vegetation changes. And extreme weather events - as well as the various skin diseases they facilitate-will continue to increase in frequency, as will skin cancers induced by more effective UV radiation.

There is a clear imperative for dermatologists to work against the processes that promote climate change, namely the protection of their patients. Notably, the American Medical Association signed the 2018 US Call to Action on Climate and Health Equity, and encourages all physicians to assume a proactive role in educating and advocating for climate health [97, 110], and multiple specialty-specific national organizations have released position statements outlining health risks due to climate change, including the AAD [111-113].
While preparing for the predicted impacts of climate change on dermatologic conditions and practice, dermatologists should consider calling upon their respective institutions to divest from the fossil fuel industry and encourage them to increase utilization of renewable energy sources [114], a position supported by the AMA (2017). Because healthcare represents the sector with the second-highest contribution to GHG emissions in the USA [115], dermatologists should implement climate-friendly interventions in their own practice [116], such as those outlined by MyGreenDoctor, which has partnered with the $\mathrm{AAD}$ and is available to AAD members. By implementing these interventions, providers can set an example for their patients, and they should make an effort to teach their patients about similar strategies for carbon footprint reduction. Just as we have trained to diagnose and treat systemic processes based on external, more visible symptoms, dermatologists should feel empowered to highlight, discuss, and use their role and unique platforms to address the various processes that underlie climate change and its effects on human health and skin disease in particular.

\section{Compliance with Ethical Standards}

Conflict of Interest Dr. Rosenbach is the Co-Chair of the American Academy of Dermatology Expert Resource Group on Climate Change and Environmental Affairs.

Human and Animal Rights and Informed Consent This article does not contain any studies with human or animal subjects performed by any of the authors.

\section{References}

Papers of particular interest, published recently, have been highlighted as:

- Of importance

1. Cook J, Nuccitelli D, Green SA, Richardson M, Winkler B, Painting R, et al. Quantifying the consensus on anthropogenic global warming in the scientific literature. Environ Res Lett. $2013 ; 8$.

2. Santer BD, Bonfils CJW, Fu Q, Fyfe JC, Hegerl GC, Mears C, et al. Celebrating the anniversary of three key events in climate change science. Nat. Clim. Chang. 2019. p. 180-2.

3. Schleussner CF, Rogelj J, Schaeffer M, Lissner T, Licker R, Fischer EM, et al. Science and policy characteristics of the Paris Agreement temperature goal. Nat. Clim. Chang. 2016. p. 827-35.

4. Wu X, Nethery RC, Sabath BM, Braun D, Dominici F. Exposure to air pollution and COVID-19 mortality in the United States: a nationwide cross-sectional study. medRxiv [Internet]. 2020;2020.04.05.20054502. Available from: https://www. medrxiv.org/content/10.1101/2020.04.05.20054502v2

5. Sanchez-Lorenzo, Arturo, et al. "Arctic Oscillation: possible trigger of COVID-19 outbreak." arXiv preprint arXiv:2005.03171 (2020). 
6. Ebi KL, Frumkin H, Hess JJ. Protecting and promoting population health in the context of climate and other global environmental changes. Anthropocene. 2017a.

7. Ebi KL, Ogden NH, Semenza JC, Woodward A. Detecting and attributing health burdens to climate change. Environ Health Perspect. 2017b;125:085004.

8. Kavanagh MM, Thirumurthy H, Katz R, Ebi KL, Beyrer C, Headley J, et al. Ending pandemics: U.S. foreign policy to mitigate today's major killers, tomorrow's outbreaks, and the health impacts of climate change. J Int Aff. 2019/2020;73(1):49-68.

9. World Health Organization. Climate change and human health risks and responses. Summary. 2003, ISBN 9241590815.

10. World Economic Forum. The global risks report 2018 13th edition [Internet]. World Econ. Forum. 2013. Available from: www. weforum.org

11. Kaffenberger BH, Shetlar D, Norton SA, Rosenbach M. The effect of climate change on skin disease in North America. J Am Acad Dermatol. 2017. p. 140-7. General overview of dermatologic implications of climate change, including variations in endemic and arboviral disease distributions, diseases associated with extreme weather events, and increased skin cancer risk.

12. Stocker TF, Qin D, Plattner GK, Tignor MMB, Allen SK, Boschung J, et al. Climate change 2013 the physical science basis: Working Group I contribution to the fifth assessment report of the intergovernmental panel on climate change. Clim. Chang. 2013 Phys Sci Basis Work Gr I Contrib to Fifth Assess Rep Intergov Panel Clim Chang 2013.

13. Le Quéré C, Jackson RB, Jones MW, Smith AJP, Abernethy S, Andrew RM, et al. Temporary reduction in daily global $\mathrm{CO} 2$ emissions during the COVID-19 forced confinement. Nat Clim Chang [Internet]. 2020;1-7. Available from: http://www.nature. com/articles/s41558-020-0797-x

14. Ogden NH, St.-Onge L, Barker IK, Brazeau S, Bigras-Poulin M, Charron DF, et al. Risk maps for range expansion of the Lyme disease vector, Ixodes scapularis, in Canada now and with climate change. Int J Health Geogr. 2008;7:24.

15. Ogden NH, Lindsay LR, Morshed M, Sockett PN, Artsob H. The emergence of Lyme disease in Canada. Cmaj. 2009. p. 1221-4.

16. Otten A, Fazil A, Chemeris A, Breadner P, Ng V. Prioritization of vector-borne diseases in Canada under current climate and projected climate change. Microb Risk Anal. 2020;14.

17. Kilpatrick AM, Randolph SE. Drivers, dynamics, and control of emerging vector-borne zoonotic diseases. Lancet. 2012. p. 194655 .

18. Centers for Disease Control and Prevention. Press release, CDC provides estimate of Americans diagnosed with Lyme disease each year. https://www.cdc.gov/media/releases/2013/p0819lyme-disease.html. 2013;Accessed Novemeber 2013.

19. Centers for Disease Control and Prevention. Lyme disease data and statistics [Internet]. http://www.cdc.gov/lyme/stats/index. html. 2012. p. Accessed June 2012. Available from: http://www. cdc.gov/lyme/stats/index.html.

20. Rosenberg R, Lindsey NP, Fischer M, Gregory CJ, Hinckley AF, Mead PS, et al. Vital signs: trends in reported vectorborne disease cases - United States and territories, 2004-2016. Morb Mortal Wkly Rep. 2018;67:496-501 Provides a general overview of the variations in vectorborne disease distributions due to climate change.

21. Nelson CA, Saha S, Kugeler KJ, Delorey MJ, Shankar MB, Hinckley AF, et al. Incidence of clinician-diagnosed Lyme disease, United States, 2005-2010. Emerg Infect Dis. 2015;21:162531.

22. Peterson AT, Shaw J. Lutzomyia vectors for cutaneous leishmaniasis in Southern Brazil: ecological niche models, predicted geographic distributions, and climate change effects. Int $\mathrm{J}$ Parasitol. 2003;33:919-31.

23. Cardenas R, Sandoval CM, Rodríguez-Morales AJ, FrancoParedes C. Impact of climate variability in the occurrence of leishmaniasis in northeastern Colombia. Am J Trop Med Hyg. 2006; 75:273-7.

24. Cross ER, Hyams KC. The potential effect of global warming on the geographic and seasonal distribution of Phlebotomus papatasi in Southwest Asia. Environ Health Perspect. 1996;104:724-7.

25. González C, Wang O, Strutz SE, González-Salazar C, SánchezCordero V, Sarkar S. Climate change and risk of leishmaniasis in North America: predictions from ecological niche models of vector and reservoir species. PLoS Negl Trop Dis. 2010;4:e585.

26. Mcllwee BE, Weis SE, Hosler GA. Incidence of endemic human cutaneous leishmaniasis in the United States. JAMA Dermatology. 2018;154:1032-9.

27. Garza M, Feria Arroyo TP, Casillas EA, Sanchez-Cordero V, Rivaldi CL, Sarkar S. Projected future distributions of vectors of Trypanosoma cruzi in North America under climate change scenarios. PLoS Negl Trop Dis. 2014;8:e2818.

28. Lynn MK, Bossak BH, Sandifer PA, Watson A, Nolan MS. Contemporary autochthonous human Chagas disease in the USA. Acta Trop. 2020;205:105361.

29. Horton A. A bloodsucking 'kissing bug' was found in Delaware. Beware its poop. Washington Post, April 25, 2019. Accessed online, June 4, 2020.

30. Suk JE, Semenza JC. From global to local: vector-borne disease in an interconnected world. Eur J Public Health. 2014. p. 531-2.

31. Rezza G. Dengue and Chikungunya: long-distance spread and outbreaks in naïve areas. Pathog. Glob. Health. 2014.

32. Tabachnick WJ. Climate change and the arboviruses: lessons from the evolution of the dengue and yellow fever viruses. Annu Rev Virol. 2016;3:125-45.

33. Robert MA, Christofferson RC, Weber PD, Wearing HJ. Temperature impacts on dengue emergence in the United States: investigating the role of seasonality and climate change. Epidemics. 2019;28:100344.

34. Campbell KM, Haldeman K, Lehnig C, Munayco CV, Halsey ES, Laguna-Torres VA, et al. Weather regulates location, timing, and intensity of dengue virus transmission between humans and mosquitoes. PLoS Negl Trop Dis. 2015;9:1-26.

35. An DTM, Rocklöv J. Epidemiology of dengue fever in Hanoi from 2002 to 2010 and its meteorological determinants. Glob Health Action. 2014;7.

36. Brady OJ, Hay SI. The global expansion of dengue: how Aedes aegypti mosquitoes enabled the first pandemic arbovirus. Annu Rev Entomol. 2020;65:191-208.

37. Kamiya T, Greischar MA, Wadhawan K, Gilbert B, Paaijmans K, Mideo N. Temperature-dependent variation in the extrinsic incubation period elevates the risk of vector-borne disease emergence. Epidemics. 2020;30:100382.

38. Ryan SJ, Carlson CJ, Mordecai EA, Johnson LR. Global expansion and redistribution of Aedes-borne virus transmission risk with climate change. PLoS Negl Trop Dis. 2018;13.

39. Bandyopadhyay D, Ghosh S. Mucocutaneous manifestations of Chikungunya fever. Indian J Dermatol. 2010. p. 64-7.

40. Tipayamongkholgul M, Fang CT, Klinchan S, Liu CM, King CC. Effects of the El Niño-Southern Oscillation on dengue epidemics in Thailand, 1996-2005. BMC Public Health. 2009;9.

41. Paixão ES, Barreto F, Da Glória Teixeira M, Da Conceição N Costa M, Rodrigues LC. History, epidemiology, and clinical manifestations of Zika: a systematic review. Am. J. Public Health. 2016. p. 606-12.

42. Farahnik B, Beroukhim K, Blattner CM, Young J. Cutaneous manifestations of the Zika virus. J. Am. Acad. Dermatol. 2016. P. 1286-7. 
43. Bogoch II, Brady OJ, Kraemer MUG, German M, Creatore MI, Kulkarni MA, et al. Anticipating the international spread of Zika virus from Brazil. Lancet. 2016. p. 335-6.

44. Gardner LM, Chen N, Sarkar S. Global risk of Zika virus depends critically on vector status of Aedes albopictus. Lancet Infect. Dis. 2016. P. 522-3.

45. Ng V, Fazil A, Gachon P, Deuymes G, Radojević M, Mascarenhas M, et al. Assessment of the probability of autochthonous transmission of chikungunya virus in Canada under recent and projected climate change. Environ Health Perspect. 2017;125:067001.

46. Stewart CL, Chu EY, Introcaso CE, Schaffer A, James WD. Coxsackievirus a6-induced hand-foot-mouth disease. JAMA Dermatology. 2013;149:1419-21.

47. Liu W, Ji H, Shan J, Bao J, Sun Y, Li J, et al. Spatiotemporal dynamics of hand-foot-mouth disease and its relationship with meteorological factors in Jiangsu Province, China. PLoS One. $2015 ; 10$.

48. Lee CCD, Tang JH, Hwang JS, Shigematsu M, Chan TC. Effect of meteorological and geographical factors on the epidemics of hand, foot, and mouth disease in island-type territory. East Asia Biomed Res Int. 2015;2015.

49. Zhang W, Du Z, Zhang D, Yu S, Hao Y. Quantifying the adverse effect of excessive heat on children: An elevated risk of hand, foot and mouth disease in hot days. Sci Total Environ. 2016;541:194 9.

50. Du Z, Lawrence WR, Zhang W, Zhang D, Yu S, Hao Y. Interactions between climate factors and air pollution on daily HFMD cases: a time series study in Guangdong. China Sci Total Environ. 2019;656:1358-64.

51. Coates SJ, Davis MDP, Andersen LK. Temperature and humidity affect the incidence of hand, foot, and mouth disease: a systematic review of the literature - a report from the International Society of Dermatology Climate Change Committee. Int J Dermatol. 2019. p. 388-99.

52. Litvintseva AP, Marsden-Haug N, Hurst S, Hill H, Gade L, Driebe EM, et al. Valley fever: finding new places for an old disease: Coccidioides immitis found in Washington state soil associated with recent human infection. Clin Infect Dis. 2015;60:e1-3.

53. Shiu J, Thai M, Elsensohn AN, Nguyen NQ, Lin KY, Cassarino DS. A case series of primary cutaneous coccidioidomycosis after a record-breaking rainy season. JAAD Case Reports. 2018;4:412-4.

54. Marsden-Haug N, Goldoft M, Ralston C, Limaye AP, Chua J, Hill $\mathrm{H}$, et al. Coccidioidomycosis acquired in Washington state. Clin Infect Dis. 2013;56:847-50.

55. Ampel NM. What 's behind the increasing rates of coccidioidomycosis in Arizona and California? Curr Infect Dis Rep. 2010;12: 211-6.

56. Park BJ, Sigel K, Vaz V, Komatsu K, McRill C, Phelan M, et al. An epidemic of Coccidioidomycosis in Arizona associated with climatic changes, 1998-2001. J Infect Dis. 2005;191:1981-7.

57. Gorris ME, Treseder KK, Zender CS, Randerson JT. Expansion of Coccidioidomycosis endemic regions in the United States in response to climate change. GeoHealth. 2019;3:308-27.

58. Stillman JH. Heat waves, the new normal: Summertime temperature extremes will impact animals, ecosystems, and human communities. Physiology. 2019. P. 86-100.

59. Sato K, Kang WH, Saga K, Sato KT. Biology of sweat glands and their disorders. I. Normal sweat gland function. J Am Acad Dermatol. 1989;20:537-63.

60. WHO. COP24 special report: health and climate change. World Health Organisation. Licence: CC BY-NC-SA 3.0 IGO. Who [Internet]. 2018; Available from: https://apps.who.int/iris/ bitstream/handle/10665/276405/9789241514972-eng.pdf?ua=1
61. Anderson BG, Bell ML. Weather-related mortality: how heat, cold, and heat waves affect mortality in the United States. Epidemiology. 2009;20:205-13.

62. Koohgoli R, Hudson L, Naidoo K, Wilkinson S, Chavan B, BirchMachin MA. Bad air gets under your skin. Exp Dermatol. 2017;26:384-7 Illustrates the impacts of air pollution on dermatological disease.

63. Brotz L, Cheung WWL, Kleisner K, Pakhomov E, Pauly D. Increasing jellyfish populations: trends in large marine ecosystems. Hydrobiologia. 2012;690:3-20.

64. Geetha S, Yogesh Kumar JS, Mohapatra A, Sornaraj R. Occurrence of portuguese man-of war along digha coast, West Bengal: a threat to tourists and fisherfolk. Indian J Geo-Marine Sci. 2019;48:96-8.

65. Needleman RK, Neylan IP, Erickson TB. Environmental and ecological effects of climate change on venomous marine and amphibious species in the wilderness. Wilderness Environ Med. 2018;29:343-56.

66. Raskoff KA. The impact of El Niño events on populations of mesopelagic hydromedusae. Hydrobiologia. 2001. p. 121-9.

67. Rose JB, Epstein PR, Lipp EK, Sherman BH, Bernard SM, Patz JA. Climate variability and change in the United States: potential impacts on water- and foodborne diseases caused by microbiologic agents. Environ Health Perspect. 2001;109:211-21.

68. Cheng AC, Jacups SP, Gal D, Mayo M, Currie BJ. Extreme weather events and environmental contamination are associated with case-clusters of melioidosis in the Northern Territory of Australia. Int J Epidemiol. 2006;35:323-9.

69. Hill S. Aquatic Dermatoses. Harper's Textb Pediatr Dermatology. 2019:746-9.

70. Soldánová M, Selbach C, Kalbe M, Kostadinova A, Sures B. Swimmer's itch: etiology, impact, and risk factors in Europe. Trends Parasitol. 2013. p. 65-74.

71. Brant SV, Loker ES. Schistosomes in the Southwest United States and their potential for causing cercarial dermatitis or swimmer's itch. J Helminthol. 2009;83:191-8.

72. Takemura AF, Chien DM, Polz MF. Associations and dynamics of vibrionaceae in the environment, from the genus to the population level. Front. Microbiol. 2014.

73. Froelich BA, Daines DA. In hot water: effects of climate change on Vibrio-human interactions. Environ Microbiol. 2020.

74. Martinez-Urtaza J, Bowers JC, Trinanes J, DePaola A. Climate anomalies and the increasing risk of Vibrio parahaemolyticus and Vibrio vulnificus illnesses. Food Res Int. 2010;43:1780-90.

75. Baker-Austin C, Oliver JD, Alam M, Ali A, Waldor MK, Qadri F, et al. Vibrio spp. Infections Nat Rev Dis Prim. 2018;4.

76. Andersen LK. Global climate change and its dermatological diseases. Int J Dermatol. 2011;50:601-3. 10.

77. Patz JA, Vavrus SJ, Uejio CK, McLellan SL. Climate change and waterborne disease risk in the Great Lakes Region of the U.S. Am. J. Prev. Med. 2008. p. 451-8.

78. Semenza JC, Herbst S, Rechenburg A, Suk JE, Höser C, Schreiber $\mathrm{C}$, et al. Climate change impact assessment of food- and waterborne diseases. Crit Rev Environ Sci Technol. 2012;42:857-90.

79. Bandino JP, Hang A, Norton SA. The infectious and noninfectious dermatological consequences of flooding: a field manual for the responding provider. Am. J. Clin. Dermatol. 2015. p. 399-424.

80. Dayrit JF, Bintanjoyo L, Andersen LK, Davis MDP. Impact of climate change on dermatological conditions related to flooding: update from the International Society of Dermatology Climate Change Committee. Int J Dermatol. 2018. p. 901-10. Summarizes the literature on dermatologic conditions that can arise or be exacerbated after flood events, such as skin or wound infections, inflammatory skin disease, and chronic dermatological conditions. 
81. Warraich H, Zaidi AKM, Patel K. Floods in Pakistan: a public health crisis. Bull World Health Organ. 2011;89:236-7.

82. Noe R, Cohen AL, Lederman E, Gould LH, Alsdurf H, Vranken $\mathrm{P}$, et al. Skin disorders among construction workers following hurricane Katrina and hurricane Rita: an outbreak investigation in New Orleans. Louisiana Arch Dermatol. 2007;143:1393-8.

83. Vachiramon V, Busaracome P, Chongtrakool P, Puavilai S. Skin diseases during floods in Thailand. J Med Assoc Thail. 2008;91: 479-84.

84. Jablecki J, Norton SA, Keller R, DeGraw C, Ratard R, StraifBourgeois $\mathrm{S}$, et al. Infectious disease and dermatologic conditions in evacuees and rescue workers after hurricane Katrina - Multiple states, August-September, 2005. J Am Med Assoc. 2005. p. 2158-60.

85. Cheng AC, Currie BJ. Melioidosis: epidemiology, pathophysiology, and management. Clin Microbiol Rev. 2005. p. 383-416.

86. Fanfair RN, Benedict K, Bos J, Bennett SD, Lo YC, Adebanjo T, et al. Necrotizing cutaneous mucormycosis after a tornado in Joplin, Missouri, in 2011. N Engl J Med. 2012;367:2214-25.

87. Limmathurotsakul D, Golding N, Dance DAB, Messina JP, Pigott DM, Moyes CL, et al. Predicted global distribution of Burkholderia pseudomallei and burden of melioidosis. Nat Microbiol. 2016;1.

88. Liu CL, Huang JJ, Lin HC, Huang ST, Liu DP. Investigation and analysis of melioidosis outbreak after Typhoon Nanmadol in Southern Taiwan, 2011. Int J Infect Dis. 2012;16:e351.

89. Wiersinga WJ, Virk HS, Torres AG, Currie BJ, Peacock SJ, Dance DAB, et al. Melioidosis. Nat Rev Dis Prim. 2018;4.

90. Urbach F. Ultraviolet radiation and skin cancer of humans. J Photochem Photobiol B Biol. 1997. p. 3-7.

91. Slaper H, Velders GJ m., Matthijsen J. Ozone depletion and skin cancer incidence: a source risk approach. J Hazard Mater. 1998. p. 77-84.

92. Norval M, Lucas RM, Cullen AP, De Gruijl FR, Longstreth J, Takizawa Y, et al. The human health effects of ozone depletion and interactions with climate change. Photochem. Photobiol. Sci. 2011. p. 199-225.

93. van der Leun JC, de Gruijl FR. Climate change and skin cancer. Photochem Photobiol Sci. 2002;1:324-6.

94. Van Der Leun JC, Piacentini RD, De Gruijl FR. Climate change and human skin cancer. Photochem Photobiol Sci. 2008;7:730-3.

95. Dobbinson S, Wakefield M, Hill D, Girgis A, Aitken JF, Beckmann K, et al. Prevalence and determinants of Australian adolescents' and adults' weekend sun protection and sunburn, summer 2003-2004. J Am Acad Dermatol. 2008;59:602-14.

96. Clayton, S., Manning, C.M., Krygsman, K., Speiser M. Mental health and our changing climate: impacts, implications, and guidance. Washington, D.C.: American Psychological Association, and ecoAmerica. Am Psychol Assoc [Internet]. 2017;36. Available from: http://www.apa.org/news/press/releases/2017/ 03/mental-health-climate.pdf

97. Schachtel A, Boos MD. Pediatric dermatology and climate change: an argument for the pediatric subspecialist as public health advocate. Pediatr Dermatol. 2019;36:564-6.

98. Nguyen GH, Andersen LK, Davis MDP. Climate change and atopic dermatitis: is there a link? Int J Dermatol. 2019. p. 279-82.

99. Kim KE, Cho D, Park HJ. Air pollution and skin diseases: adverse effects of airborne particulate matter on various skin diseases. Life Sci. 2016. p. 126-34.
100. Araviiskaia E, Berardesca E, Bieber T, Gontijo G, Sanchez Viera $\mathrm{M}$, Marrot L, et al. The impact of airborne pollution on skin. J. Eur. Acad. Dermatology Venereol. 2019. p. 1496-505.

101. Ren Z, Hsu D, Brieva J, Silverberg JI. Association between climate, pollution and hospitalization for pemphigus in the USA. Clin Exp Dermatol. 2019;44:135-43.

102. Stojan G, Curriero F, Kvit A, Petri MA. Fri0656 Environmental and atmospheric factors in systemic lupus erythematosus: a regression analysis. 2019. p. 1025.2-1027.

103. Grandi C, Borra M, Militello A, Polichetti A. Impact of climate change on occupational exposure to solar radiation. Ann Ist Super Sanita. 2016;52:343-56.

104. Hart PH, Norval M, Byrne SN, Rhodes LE. Exposure to ultraviolet radiation in the modulation of human diseases. Annu Rev Pathol Mech Dis. 2019;

105. Pirozzi CS, Mendoza DL, Xu Y, Zhang Y, Scholand MB, Baughman RP. Short-term particulate air pollution exposure is associated with increased severity of respiratory and quality of life symptoms in patients with fibrotic sarcoidosis. Int J Environ Res Public Health. 2018;

106. Deubelbeiss U, Gemperli A, Schindler C, Baty F, Brutsche MH. Prevalence of sarcoidosis in Switzerland is associated with environmental factors. Eur Respir J. 2010;35:1088-97.

107. Mohan JE, Ziska LH, Schlesinger WH, Thomas RB, Sicher RC, George $\mathrm{K}$, et al. Biomass and toxicity responses of poison ivy (Toxicodendron radicans) to elevated atmospheric $\mathrm{CO} 2$. Proc Natl Acad Sci U S A. 2006;103:9086-9.

108. Buters JTM. Impacts of climate change on allergenicity. Impacts Clim Chang Allergens Allerg Dis. 2016. p. 74-91.

109. Kollmann J, Strobel BW, Hansen HCB. Climate change, invasive species and toxic plant substances in soil and water. IOP Conf Ser Earth Environ Sci. 2009;6:302022.

110. American Medical Association. Global climate change and human health H-135.938. https://policysearch.ama-assn.org/policyfinder/ detail/climate\%20change?uri=\%2FAMADoc\%2FHOD.xml-0309.xml. Updated 2014. Accessed Jun 7, 2020.

111. Medical Society Policy Statements Archives - The Medical Society Consortium on Climate and Health (MSCCH). (2020, April 18). Retrieved from https://medsocietiesforclimatehealth. org/category/medical-society-policy-statements/

112. Crowley RA. Climate change and health: a position paper of the American college of physicians. Ann Intern Med. 2016;164:60810.

113. American Academy of Dermatology. Position statement on climate and health. Available at https://www.aad.org/forms/ policies/up- loads/ps/ps\%20-\%20climate\%20and\%20health.pdf. Published July 28; 2018. Accessed June 6, 2020.

114. Tillmann T, Currie J, Wardrope A, McCoy D. Fossil fuel companies and climate change: the case for divestment. BMJ. 2015;350.

115. Sherman JD, MacNeill A, Thiel C. Reducing pollution from the health care industry. J Am Med Assoc. 2019. p. 1043-4.

116. Fathy RA, Nelson CA, Barbieri JS. Combating climate change in the clinic: cost-effective strategies to decrease the carbon footprint of outpatient dermatologic practice. Int J Women's Dermatol Under Review.

Publisher's Note Springer Nature remains neutral with regard to jurisdictional claims in published maps and institutional affiliations. 